OPEN

SUBJECT AREAS: MEDICAL RESEARCH

PHYSIOLOGY

Received

31 March 2014

Accepted

18 June 2014

Published

5 August 2014

Correspondence and requests for materials should be addressed to F.K. (kilicfusun@uams. edu)

\section{Effect of serotonin on platelet function in cocaine exposed blood}

\author{
Endrit Ziu', Coedy Hadden', Yicong Li' ', Curtis Lee Lowery III', Preeti Singh', Serra S. Ucer', \\ Charles P. Mercado' , Howard H. Gu² \& Fusun Kilic'
}

'Department of Biochemistry and Molecular Biology, College of Medicine, University of Arkansas for Medical Sciences,
${ }^{2}$ Department of Pharmacology, College of Medicine, Ohio State University.

5-hydroxytryptamine (5-HT) reuptake inhibitors counteract the pro-thrombotic effect of elevated plasma 5-HT by down-regulating the 5-HT uptake rates of platelets. Cocaine also down-regulates the platelet 5-HT uptake rates but in contrast, the platelets of cocaine-injected mice show a much higher aggregation rate than the platelets of control mice. To examine the involvement of plasma 5-HT in cocaine-mediated platelet aggregation, we studied the function of platelets isolated from wild-type and transgenic, peripheral 5-HT knock-out (TPH1-KO) mice, and cocaine-insensitive dopamine transporter knock in (DAT-KI) mice. In cocaine-injected mice compared to the control mice, the plasma 5-HT level as well as the surface level of P-selectin was elevated; in vitro platelet aggregation in the presence of type I fibrillar collagen was enhanced. However, cocaine injection lowered the 5-HT uptake rates of platelets and increased the plasma 5-HT levels of the DAT-KI mice but did not change their platelets aggregation rates further which are already hyper-reactive. Furthermore, the in vitro studies supporting these in vivo findings suggest that cocaine mimics the effect of elevated plasma 5-HT level on platelets and in 5-HT receptor- and transporter-dependent pathways in a two-step process propagates platelet aggregation by an additive effect of 5-HT and nonserotonergic catecholamine.

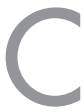

ocaine use is associated with complications in the cardiovascular (CV) system directly and indirectly via stimulating the sympathetic nervous system. In peripheral tissue, cocaine produces a sympathomimetic response by inhibiting the reuptake of serotonin (5-HT) and catecholamine leading to a transient bradycardia followed by tachycardia, hypertension and acute thrombosis in coronary arteries. However, it is unclear if the hyper-reactivity of platelets originating from catecholamine or different pathogenic origins differentially predisposes platelets to thrombosis.

Studies agree that the development of cocaine-related CV problems does not require a preexisting vascular disease $^{1}$. Even in the absence of systemic platelet activation, endothelial dysfunction, or CV complications, cocaine is associated with acute thrombosis of coronary arteries ${ }^{1-3}$; however, the mechanism by which cocaine predisposes to platelet-dependent thrombus formation is poorly understood.

Cocaine is a potent antagonist of 5-HT transporter, SERT and catecholamine transporters, norepinephrine (NE) transporter (NET) and dopamine (DA) transporter (DAT). Specifically, DAT is the primary target for cocain $^{4-6}$. Based on the similarities of these transporters and their receptors in between platelets and central nervous system, the inhibitory effect of cocaine on platelet is expected to be strong enough and elevates their plasma levels. Platelet membrane has SERT and residual level of NET but DA uptake of platelet is still controversial; specifically the $\alpha$-granules of platelet contain DA, but there is no indication for DAT in platelet. On the other hand, DATs are expressed in the stomach, pancreas, as well as in lymphocytes. Cocaine inhibits DAT at these sites, and the secretion of $\alpha$-granules from activated platelets elevate the plasma DA level ${ }^{7}$. While some studies accept the involvements of plasma catecholamines in platelet activation and aggregation, there are some controversial reports not accepting this ${ }^{8}$.

Cocaine acts as a ligand on SERT and reduces the 5-HT reuptake rates of the cells. 5-HT is synthesized and secreted into blood by enterochromaffin cells of the intestine but its plasma concentration is primarily regulated by SERT on the plasma membrane of platelet via a saturable reuptake mechanism. Once in the platelet cytoplasm, 5-HT molecules are sequestered by the vesicular monoamine transporter type 2 (VMAT2) into intracellular dense granules. Notably, the 5-HT concentration in blood plasma is in the low nanomolar range, but the dense granules of resting platelets store millimolar concentrations of 5-HT ${ }^{10-11}$. The actions of 5-HT are mediated by different types of receptors but terminated by a single transporter, SERT ${ }^{12}$. Therefore, plasma vs. platelet 5-HT ratio, primarily regulated by SERT, plays an important role in CV system. 

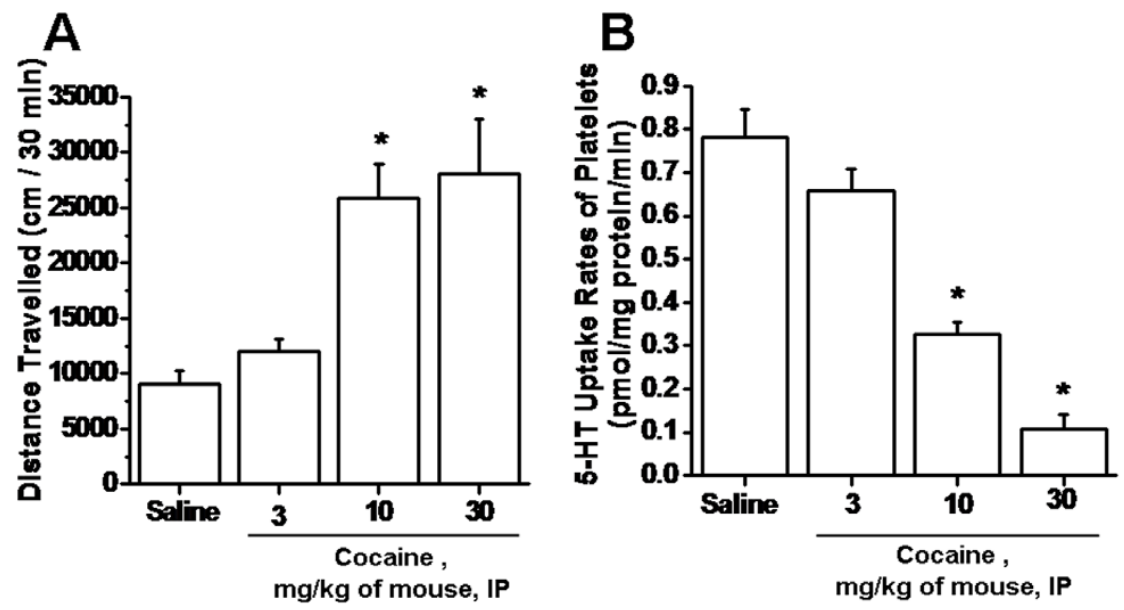

Figure $1 \mid$ (A) Locomotor Activity. C57BL/6J mice were injected with cocaine at various concentrations, 0-3-10-30 mg/kg. Their locomotor activities were found as increased in $30 \mathrm{mg} / \mathrm{kg}$, cocaine injected mice with relative to the saline-injected control group. (B) 5-HT uptake rates of platelets. Elevated cocaine concentration was associated with a $61 \%$ decrease in the platelet 5-HT uptake rate compared to control mice. All assays were performed in triplicate ( $\mathrm{n}=5$ group). Asterisks indicate statistical difference between saline- and cocaine-injected $(*)$ mice.

Notably, 5-HT is an independent risk factor for platelet aggregation and for thrombus formation in animals and humans ${ }^{10,13-17}$. The involvement of plasma 5-HT in platelet aggregation process may also occur in $5-\mathrm{HT}_{2 \mathrm{~A}}$-independent, SERT-dependent signaling pathways $^{13-23}$. Interestingly, the pharmacological block of the $5-\mathrm{HT}_{2 \mathrm{~A}}$ receptor elevates the 5-HT uptake rates and inhibits 5-HT-induced platelet activation in animal models of hypertension ${ }^{18}$, as well as ex vivo platelet aggregation ${ }^{17}$. Selective 5 -HT reuptake inhibitors (SSRI) lowers the 5-HT uptake rates of platelets and predispose to platelet dysfunction and bleeding ${ }^{13,14,18}$. In an earlier study, we showed that when 5-HT-infused mice were treated with paroxetine, an SSRI, the 5-HT uptake rates of platelets as well as the platelet content of 5-HT were reduced but in contrast the markers of platelet activation associated with a pro- aggregation phenotype were reduced ${ }^{13}$. These studies strongly infer the involvement of 5-HT in platelet aggregation by acting as ligand for the $5-\mathrm{HT}_{2 \mathrm{~A}}$ receptor ${ }^{19,20}$ and SERT situated on the platelet plasma membrane ${ }^{13,21-23}$.

In the current study, we are exploring the involvement of 5-HT in cocaine-mediated platelet activation, we studied the platelets of mice knocked in with cocaine-insensitive dopamine transporter, DAT$\mathrm{KI}^{24}$. The injection of cocaine on DAT-KI mice did not change the aggregation rates of platelets further but reduced their 5-HT uptake rates significantly which caused an elevation in plasma 5-HT levels. Following the cocaine-injection, the plasma 5-HT levels and the response of platelet to collagen were elevated in wild-type, peripheral 5 -HT KO (TPH1-KO $)^{21}$. Based on our results, we hypothesize that cocaine mimics the combined effect that SERT and $5-\mathrm{HT}_{2 \mathrm{~A}}$ play together in a two-step process to propagate the platelet aggregation by additive effect of 5-HT and the nonserotonergic catecholamine. Findings from these studies will impact the field in terms of demonstrating the mechanism by which serotonergic and nonserotonergic catecholamines play a role in the cocaine-mediated platelet aggregation process.

\section{Results}

Cocaine and 5-HT in circulation system. Our earlier studies demonstrated that 5-HT concentration in platelet cytoplasm is an important factor in promoting the aggregation ability of platelets. Here, we are investigating the involvement of 5-HT on cocaine-mediated platelet aggregation rates in detail.

Mice were injected with cocaine at different doses (ranging from 10 to $30 \mathrm{mg} / \mathrm{kg}$, intraperitoneally) over 30 minutes; their locomotor activities were measured and found to be elevated by 2 -fold relative to control (saline-injected) mice (Fig. 1A).
At the end of $30 \mathrm{~min}$ of cocaine injection, platelets were isolated from the blood samples of the each group of mice and their 5-HT uptake rates were measured $(\mathrm{P}<0.01)$ (Fig. $1 \mathrm{~B}$ and Table 1$)$. The 5HT uptake rate of the platelets reduced in parallel to the elevated concentration of the cocaine injected to the mice. However the highest reduction in the uptake rates was found in the platelets of $30 \mathrm{mg} /$ $\mathrm{kg}$ cocaine-injected mice which was $86 \%$ lower than the control groups $(n=5)$. Therefore, in the following studies, the mice were injected with $30 \mathrm{mg} / \mathrm{kg}$ cocaine and the assays were performed $30 \mathrm{~min}$ following injections.

Comparing the platelets isolated from cocaine-injected mice with the platelets of Paroxetine-injected mice. Blood samples were analyzed using an ELISA assay to measure the 5-HT levels (Fig. 1A). As anticipated, the 5-HT concentrations in the plasma of cocaineinjected mice $(3.50 \pm 0.18 \mathrm{ng} / \mu \mathrm{l}$ blood) were 4 -fold higher than the levels in the plasma of control mice $(0.88 \pm 0.07 \mathrm{ng} / \mu \mathrm{l}$ blood $)$. Similarly, plasma 5-HT concentrations in PAR-injected mice also showed a 3.4-fold higher level compared to the control mice plasma level (5 mice per group) (Fig. 2A and Table 1). The circulating platelets counts were similar between control and the cocaine-injected mice. However, the 5-HT uptake rates of platelets of PAR and cocaine-injected mice were much lower than the control platelets' 5-HT uptake rates (Fig. 2B).

Next, in stirred platelet aggregometer the rates of percent aggregation of the platelets from control-, PAR- or cocaine-injected mice were determined as their response to stimulation with collagen $(3 \mu \mathrm{g} / \mathrm{ml})$. The representative aggregation tracings are shown (Fig. 3A) revealing an opposite response in the percent aggregation in response to collagen. While the PAR-injection reduces the extent of aggregation by $46 \%$, platelets of cocaine-injected mice showed 34\% elevation (Fig. 3A and Table 1).

The level of P-selectin on the platelet surface is a good marker for their shift from the resting stage. Therefore, the surface expression of $\mathrm{P}$-selectin on platelets isolated from cocaine-injected mice compared to control and PAR-injected mice platelets were analyzed by flow cytometry. Thus, in vivo exposure to cocaine coincides with a heightened platelet response as measured by stirred platelet aggregations and increased markers of platelet activation. In contrast, platelets of PAR-injected mice appeared to have lower aggregation rates and lower levels of surface P-selectin compared to control mice platelets (Fig. 3B. Table 1).

The significance of 5-HT plasma/platelet ratio in platelet aggregation mechanism. In an effort to understand the impact of the 


\begin{tabular}{|c|c|c|c|c|c|c|c|c|}
\hline & WT & $W T+P A R$ & WT+ Sarpo & $W T+C o c$. & TPHI-KO & $\mathrm{TPHI}-\mathrm{KO}+\mathrm{Coc}$ & DAT-KI & DAT-KI + Coc. \\
\hline $\begin{array}{c}\text { [5-HT] in plasma } \\
\text { (ng/ul blood) }\end{array}$ & $0.88 \pm 0.07$ & $2.95 \pm 0.05$ & $0.68 \pm 0.07$ & $3.50 \pm 0.18$ & u.n.d. & u.n.d. & $0.68 \pm 0.09$ & $4.1 \pm 0.17$ \\
\hline $\begin{array}{l}\text { 5-HT uptake rates } \\
\text { (pmol/min/mg } \\
\text { protein) }\end{array}$ & $0.76 \pm 0.04$ & $0.30 \pm 0.02$ & $0.92 \pm 0.05$ & $0.11 \pm 0.02$ & $0.89 \pm 0.05$ & $0.19 \pm 0.01$ & $1.01 \pm 0.1$ & $0.17 \pm 0.02$ \\
\hline $\begin{array}{l}\text { Platelet } \\
\text { aggregation }\end{array}$ & & $23 \pm 4.1$ & $38 \pm 5.71$ & $64.33 \pm 4.04$ & $30 \pm 2.83$ & $40 \pm 4.62$ & $60.67 \pm 2.31$ & $63.33 \pm 1.15$ \\
\hline $\begin{array}{l}\text { Flow cytometry } \\
\text { analysis of } \\
\text { P-selectin }\end{array}$ & $181.7 \pm 8.00$ & $110.32 \pm 9.35$ & $145.3 \pm 7.35$ & $325.21 \pm 11.2$ & $93.13 \pm 7.77$ & $7101.09 \pm 2.67$ & $297.11 \pm 8.31$ & $312.89 \pm 9.44$ \\
\hline
\end{tabular}

u.n.d. = undetectable; defined as $[5-\mathrm{HT}]<0.1 \mathrm{ng} / \mu \mathrm{l}$ or $5-\mathrm{HT}$ uptake rate less than the background accumulation of ${ }^{3} \mathrm{H}-5 \mathrm{HT}$.

environment that cocaine-injection created on platelet behavior, a mouse model was created to mimic the platelets of cocaine-injected mice. The involvement of SERT and 5-HT receptor in 5-HTmediated platelet aggregation was analyzed by injecting the mice with SSRI or 5-HT receptor blocker before or after the 5-HT infusion through osmotic mini pumps.

Our earlier studies showed that the plasma 5-HT concentration was $0.85 \pm 0.04 \mathrm{ng} / \mu \mathrm{l}$ blood for saline-infused animals $(\mathrm{n}=15)$ and $2.74 \pm 0.37 \mathrm{ng} / \mu \mathrm{l}$ blood for 5-HT-infused animals $(\mathrm{n}=15)$; at the end of 24 hours infusion, platelet count did not show a difference between blood samples from saline and 5-HT-infused mice ${ }^{13}$. Mice implanted with osmotic mini-pumps were injected with PAR (3 mg/ $\mathrm{kg})^{13,25}$ as a SERT inhibitor or Sarpogrelate (Sarpo, $\left.30 \mathrm{mg} / \mathrm{kg}\right)^{17,19,20}$ as a $5-\mathrm{HT}_{2 \mathrm{~A}}$ antagonist, either before the infusion of 5-HT started (preinfusion), or at the end of 24-hr 5-HT infusion (post-infusion) (5 mice per group). The half-life of PAR is 24-hr but Sarpo is only 12-hr. Therefore, for the pre-infusion, Sarpo injection was repeated as two doses in 12-hr periods.

The 5-HT uptake rates of the platelets from 5-HT-infused or only PAR injected mice were reduced $37 \%$ or $60 \%$ respectively, compared to the platelets of saline-infused mice (Fig. 4A). However, platelets from sarpo-injected mice showed $20 \%$ upregulation on 5-HT uptake rates. If PAR or Sarpo were injected on mice before the 5-HT-infusion was started (pre-5HT-infused), the 5-HT uptake rates of platelets were down-regulated by PAR, to the level which was found in cocaine-injected mice plasma. However, if PAR or Sarpo were injected on mice at the end of 24-hr 5-HT-infusion (Post-5HT-infu- sion), the effect of drugs on the 5-HT uptake rates were not significantly different than the control level.

Next, the responses of platelets to collagen were evaluated in drug injected pre- and post-5-HT-infused mice. The aggregation rates of the platelets isolated from Sarpo or Par injected 5-HT-infused mice appeared at similar level with the rates of control group. Interestingly, the aggregation rates of the platelets as well as the surface level of P-selectin on platelets was significantly high in 5HT infused mice as found the aggregation rates of platelets from the cocaine-injected mice (Fig. 4). Overall, both drugs, PAR and Sarpo, reduced the aggregation rates and the level of $\mathrm{P}$-selectin on the surface of platelets (Table 1 and Fig. 4B).

In vitro effects of cocaine, $5-\mathrm{HT}$, SSRI and 5- $\mathrm{HT}_{2 \mathrm{~A}}$ antagonists on platelets. Next, we were interested in determining the effects of individual drugs on platelet physiology, two types of SSRI, PAR and Citalopram $(\mathrm{CIT})^{25}$, or $5-\mathrm{HT}_{2 \mathrm{~A}}$ antagonists, Sarpo and MDL100907 ${ }^{26}$, or 5-HT, or cocaine at various concentrations were tested on platelets isolated from wild-type mice (Fig. 5). Here, in an in vitro system, the platelet aggregation rates were correlated with the 5 HT uptake rates of the platelets. Platelets were pretreated with the drugs listed above and were analyzed for their 5-HT uptake rates and the aggregation profiles to compare the effect of these drugs in both, in vitro and in vivo systems (Fig. 5). The pretreatment of platelets with SSRI and 5-HT2A blocker showed similar effects on 5-HT uptake rates as well as on the aggregation rates of platelets (Fig. 5) as they did in an in vivo setting (Fig. 4).
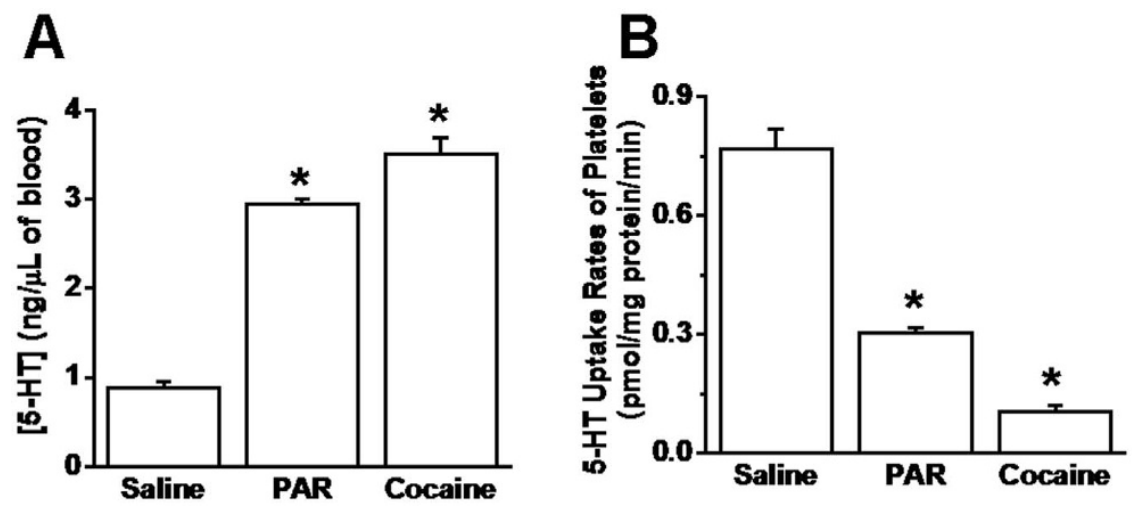

Figure $2 \mid$ (A). Blood 5-HT concentration. The 5-HT concentrations in blood samples of the saline-, PAR (3 mg/kg)- or cocaine (30 mg/kg)-injected mice were measured by a competitive ELISA technique $(0.88 \pm 0.07 \mathrm{ng} / \mu \mathrm{l}$ blood in saline-infused, and $2.95 \pm 0.05 \mathrm{ng} / \mu \mathrm{l} \mathrm{blood} \mathrm{in} \mathrm{PAR-injected,} \mathrm{and} 3.5$ $\pm 0.18 \mathrm{ng} / \mu \mathrm{l}$ blood in cocaine-injected) ${ }^{13}$. Both, cocaine and PAR-injection increased the plasma 5-HT concentration by 3.5-fold. (B) 5 -HT uptake rates of platelets. Platelets of saline- and PAR- or cocaine-injected mice were isolated and the 5-HT uptake rates of platelets measured as described previously ${ }^{13}$. Both, PAR and cocaine-injection were associated with a $61 \%$ and $85 \%$ decrease, respectively in 5 -HT uptake rates of platelets compared to the saline-infused mice. All assays were performed in triplicate $(n=5$ group). Asterisks indicate statistical difference between saline- and cocaine-injected $(*)$ mice. 

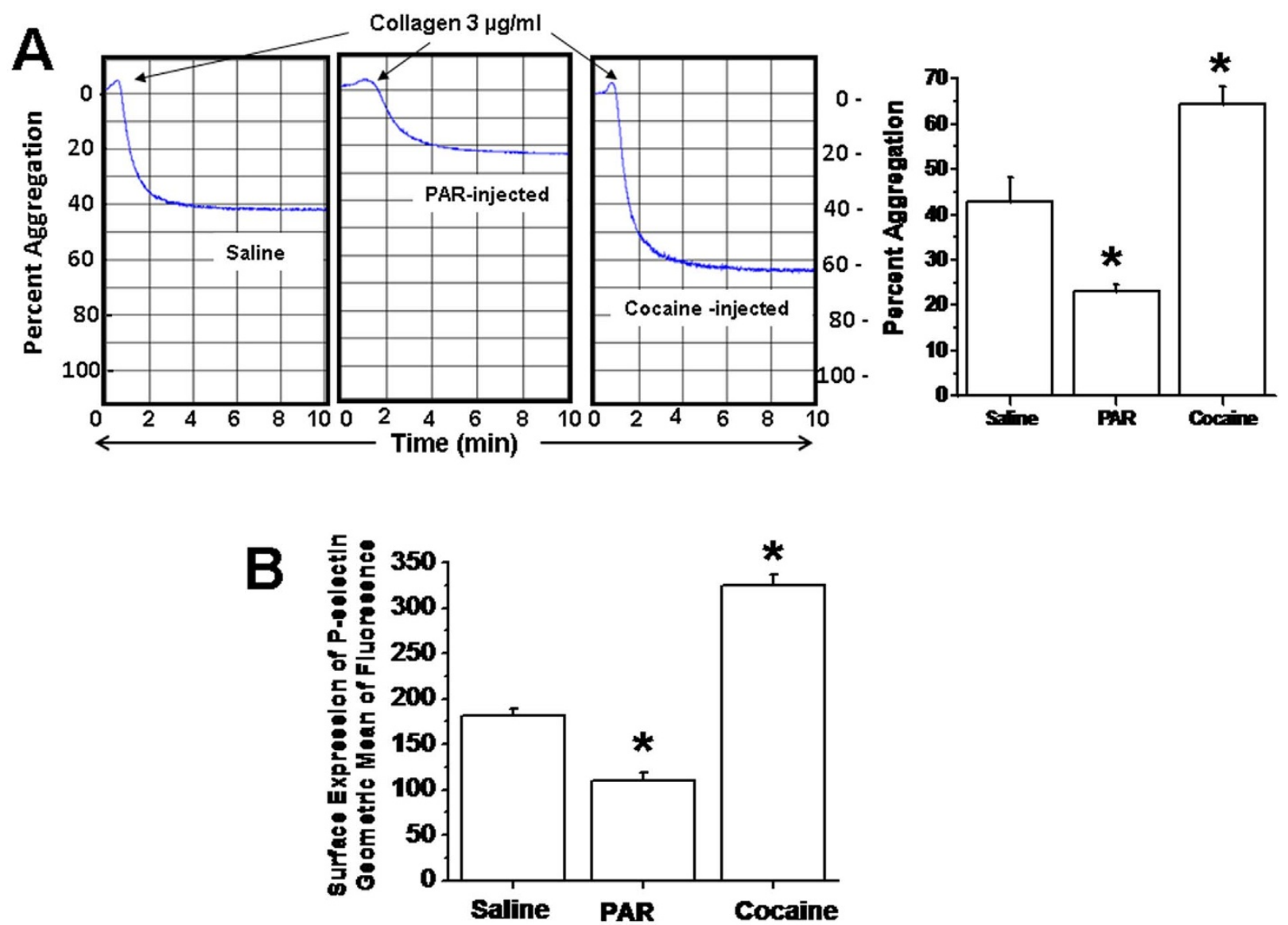

Figure $3 \mid$ (A) Platelet aggregation. Representative tracings of stirred platelet aggregation are shown. In response to stimulation with $3 \mu \mathrm{g} / \mathrm{ml}$ collagen, platelets from PAR-injected mice showed 14\% lower aggregation rate than the platelets from saline-infused mice. Interestingly, cocaine-injection was associated with a $49 \%$ increase in the aggregation rates of platelet. (B) P-selectin flow cytometry. The impact of PAR or cocaine on the platelet activity was evaluated by measuring the surface level of P-selectin. The flow cytometry data revealed a $39 \%$ decrease in the expression level of P-selectin in platelets of PAR-injected mice. However, an $80 \%$ elevation in surface expression of P-selectin was found in platelets of cocaine-injected mice. These assays were performed in triplicate $(\mathrm{n}=5$ group). Asterisks indicate statistical difference between saline- and PAR- or cocaine-injected $(*)$ mice.

However, while the cocaine effect on the 5-HT uptake rates of platelets appeared as down-regulating in both, in vivo and in vitro systems, its effect on the aggregation rates of platelets was not same. In an in vitro system, cocaine-treatment did not elevate the aggregation rates of platelets, as was seen in the aggregation rates of the platelets from cocaine-injected mice (Figs 3 and 5).

Impact of cocaine stimulation on the platelets of cocaine insensitive transgenic mice. To determine the participation of plasma 5-HT in the function of platelets in cocaine-exposed blood, here we tested the source for the cocaine-mediated platelet aggregation on transgenic mice: specifically mice lack of 5-HT in blood (TPH1$\mathrm{KO})$ and the mice knocked in with cocaine-insensitive dopamine transporter, DAT-KI. The biochemical and functional analysis of the platelets of transgenic mice were performed with or without cocaine-injection and compared the ones in control mice.

As described previously ${ }^{24}$, DAT in DAT-KI mice are 70 -fold less sensitive to cocaine but fully functional for DA uptake. Tryptophan hydroxylase 1 (TPH1)-KO mice lack the TPH1 gene that encodes the rate-limiting enzyme in peripheral 5-HT synthesis.

First the locomotor activities of WT, TPH1-KO and DAT-KI mice were monitored in the presence and absence of cocaine $(n=5)$. Cocaine $(30 \mathrm{mg} / \mathrm{kg})$ was injected intraperitoneally in mice and at the end of $30 \mathrm{~min}$ of injection, the locomotor activities of all, cocaineor saline-injected mice were measured (Fig. 6A). Interestingly DATKI mice did not show any change on their locomotor activities following cocaine injection. But the locomotor activity of salineinjected DAT-KI mice appeared 2-fold higher than the TPH1-KO and WT. Cocaine injection can be significantly seen on TPH-KO and WT mice (Fig. 6A).

Next, platelets were isolated from each group of mice and the 5HT uptake rates were measured $(\mathrm{P}<0.01)$ (Fig. 6B and Table 1). Regardless of the study model, cocaine-injection reduced the 5-HT uptake rates of their platelets $(\mathrm{n}=5)$. While, the 5-HT uptake rates of platelets isolated from DAT-KI mice were $25 \%$ and $12 \%$ higher than the uptake rates of platelets in WT or in TPH1 KO mice, respectively.

In correlating the 5-HT uptake rates with the plasma 5-HT levels, the cocaine- or control mice plasma 5-HT levels were measured (Table 1). At the end of $30 \mathrm{~min}$ of cocaine injection, platelets were counted for all models. Circulating platelets counts were unchanged as a result of $30 \mathrm{~min}$ cocaine-injection. Then, the 5-HT concentrations in platelet and in plasma were determined by ELISA. The plasma 5-HT levels of control and cocaine-injected DAT-KI mice $(\mathrm{n}=4)$ were determined as $0.68 \pm 0.09 \mathrm{ng} / \mu \mathrm{l}$ blood and $4.1 \pm$ $0.17 \mathrm{ng} / \mu$ l blood, respectively (Fig. 7A). As anticipated, cocaineinjected DAT-KI mice showed a 6.0-fold higher plasma 5-HT concentration than the 5-HT level in control DAT-KI mice blood plasma. The plasma 5-HT levels for TPH1-KO or cocaine injected counterparts appeared undetectably low.

Platelets from control- or cocaine-injected WT, DAT-KI and TPH1-KO mice were prepared in plasma and stimulated with col- 


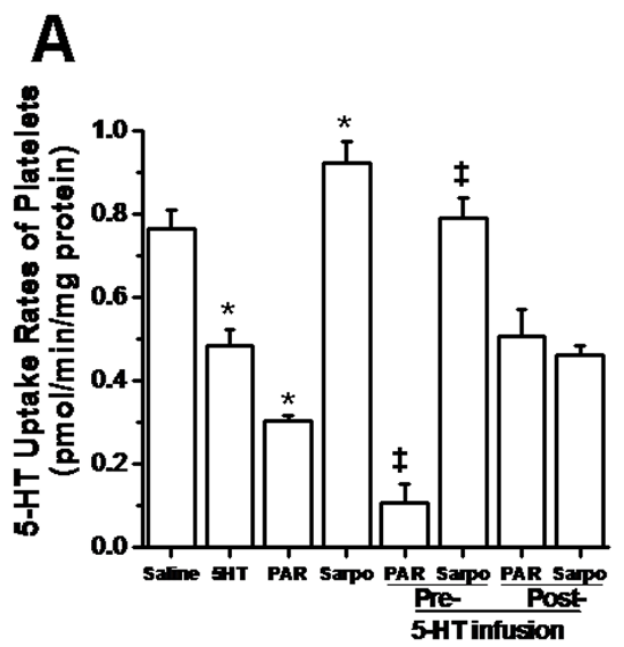

B

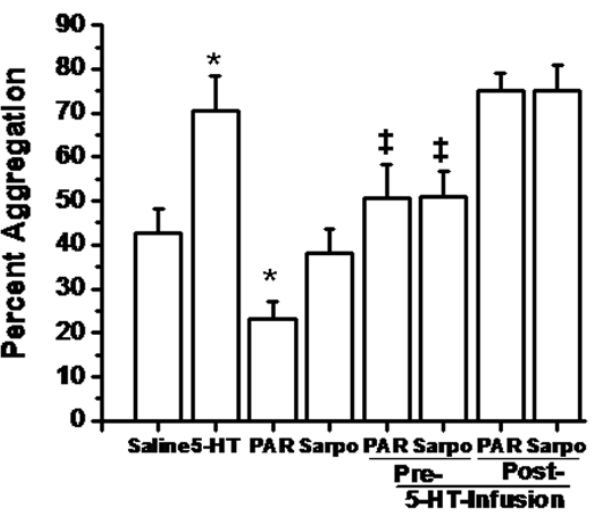

Figure $4 \mid$ Time-dependent evaluation of PAR and Sarpo on platelets. The osmotic mini-pumps were filled with $90 \pm 10 \mu \mathrm{l}$ of saline or 5-HT (dissolved in saline to provide a dose of $0.1 \mathrm{mg} / \mathrm{ml})$. One group of mice was only injected with PAR or Sarpo $(30 \mathrm{mg} / \mathrm{kg})$. The effect of PAR and Sarpo were tested on 5-HT-infused mice either by injecting the mice before the 5-HT-infusion started (Pre-) or at the end of 24 hour infusion ( $\mathrm{n}=5 \mathrm{group}$ ). At the end of 24 -hr infusion, platelets from 8 groups of mice were isolated and assayed. (A) 5-HT uptake rates. 5-HT uptake assay was performed as described in the Method section. As reported previously, elevated plasma 5-HT was associated with a 37\% decrease in 5-HT uptake rates of platelets compared to the saline-infused mice. 5-HT uptake rates of platelets were assayed in triplicate. While PAR-injection lowered the 5-HT uptake rates of platelets 60\%, Sarpo elevated their rates by $21 \%$. (B) Effect of PAR and Sarpo on platelet aggregation. The effect of PAR or Sarpo on platelet aggregation was monitored. Platelets were isolated from 8 study models of mice and stimulated with collagen and their aggregation profile was monitored in an aggregometer. Approximately $35 \%$ of the platelets from PAR-injected saline-infused mice, 54\% of platelets from PAR-injected on pre-5-HT-infused mice and 75\% of platelets from PAR-injected on post-5-HT-infused mice were aggregated at the end of $4 \mathrm{~min}$, whereas in the absence of PAR, saline-infused mice platelets showed $\sim 42 \%$ and the 5-HT-infused mice platelets showed $\sim 75 \%$ aggregation. Similarly $42 \%$ of the platelets from Sarpo-injected saline-infused mice, $51 \%$ of platelets from Sarpo-injected on pre-5-HT-infused mice and 75\% of platelets from PAR-injected on post-5-HT-infused mice were aggregated at the end of 4 min. The average of 5 measurements is presented in the bar graph. PAR- or Sarpo-injection on pre-5HT-infused mice lowered the 5-HT uptake rates of platelets to the level found in cocaine-injected mice plasma. Their rate of aggregations was also $30 \%$ higher than the aggregation rates of platelets from control group. Asterisks indicate statistical difference between saline- and PAR- or Sarpo-injected or 5-HT-infused $\left({ }^{*}\right)$; 5-HT- and PAR- or Sarpo-injected on 5-HT-infused $(\$)$ mice. All assays were performed in triplicate $(n=5$ group).

lagen $(3 \mu \mathrm{g} / \mathrm{ml})$ and tested in their stirred platelet aggregation assays. The representative aggregation tracings are shown (Fig. 7B) revealing an interesting response in the percent aggregation in response to collagen. The platelets of control or cocaine-injected DAT-KI did not show any difference. The cocaine-injection elevated the extent of aggregation by $30 \%$, platelets of cocaine-injected TPH1-KO mice (Fig. 7B and Table 1).

The surface expression of P-selectin on platelets isolated from cocaine-injected mice compared to the control mice platelets were analyzed by flow cytometry. Thus, in vivo exposure to cocaine coincides with a heightened platelet response as measured by stirred platelet aggregations and increased markers of platelet activation only for WT and TPH1-KO but not DAT-KI mice (Table 1).

\section{Discussion}

Cocaine is the second most commonly used illicit drug. Moreover, 5$10 \%$ of emergency department visits in the United States are believed to be secondary to cocaine usage and $40 \%$ of those admitted with chest pain, the most common cocaine-related medical problem ${ }^{27,28}$. Through a variety of mechanisms, cocaine increases the risk of $\mathrm{CV}$ complications specifically thrombosis ${ }^{1,2,29-33}$. Autopsy studies demonstrated the presence of coronary atherosclerosis in young cocaine users along with associated thrombus formation ${ }^{34}$; thus, cocaine use is associated with premature coronary atherosclerosis and thrombosis.

Platelets are derived from the fragmented cytoplasm of megakaryocytes and enter the circulation in an inactive form. The initial activation of platelets stabilizes them in hemostasis. Further platelet activation enlists more platelets at a fibrin-stabilized hemostatic area to form a thrombus after associating with the endothelium or each other. Platelets isolated from cocaine-injected mice appear more hyper-reactive and form thrombus as a result of elevated platelet $\alpha$-granule release ${ }^{2}$, platelet count and level of plasminogen-activator inhibitor and decreased level of antithrombin-III ${ }^{2,30,31}$. Previously published studies agree that the development of cocaine-related $\mathrm{CV}$ problems does not require preexisting vascular disease ${ }^{1}$. Even in the absence of systemic platelet activation, endothelial dysfunction, or CV complications, cocaine is associated with acute thrombosis of coronary arteries ${ }^{1-3}$; however, the mechanism by which cocaine predisposes to platelet-dependent thrombus formation is poorly understood.

The role of circulating free 5-HT in platelet adhesion, aggregation and thrombus formation has been studied by various laboratories including ours, and clinical and biochemical observations infer a complex involvement. For example, increased thrombus incidence including hypertension exhibit elevated plasma 5-HT ${ }^{35-39}$ and enhanced aggregation responses are a feature of isolated human platelets exposed to 5 - $\mathrm{HT}^{13,21}$. The 5 - $\mathrm{HT}$ signaling pathway in platelet aggregation was defined in $5-\mathrm{HT}_{2 \mathrm{~A}}$ - or SERT-dependent pathways $^{13,17,21}$.

The receptor-dependent pathway is related to plasma 5-HT signaling which is initiated by an interaction between plasma 5-HT and $5-\mathrm{HT}_{2 \mathrm{~A}}$, a G-protein coupled receptor on the platelet surface. 5-HT signaling transduced by $5-\mathrm{HT}_{2 \mathrm{~A}}$ mobilizes calcium from intracellular stores to trigger the vesicular release of pro-coagulant molecules from $\alpha$-granules ${ }^{13,21,22}$. Studies demonstrated that $5-\mathrm{HT}_{2 \mathrm{~A}}$ antagonist elevates the 5-HT uptake rates of platelets but the blocked 5-HT signaling can neither mobilize the intracellular calcium nor lead to the secretion of granules. Therefore in blood exposed to $5-\mathrm{HT}_{2 \mathrm{~A}}$ antagonist aggregation rates of platelets appear even lower than the physiological level ${ }^{17}$. 

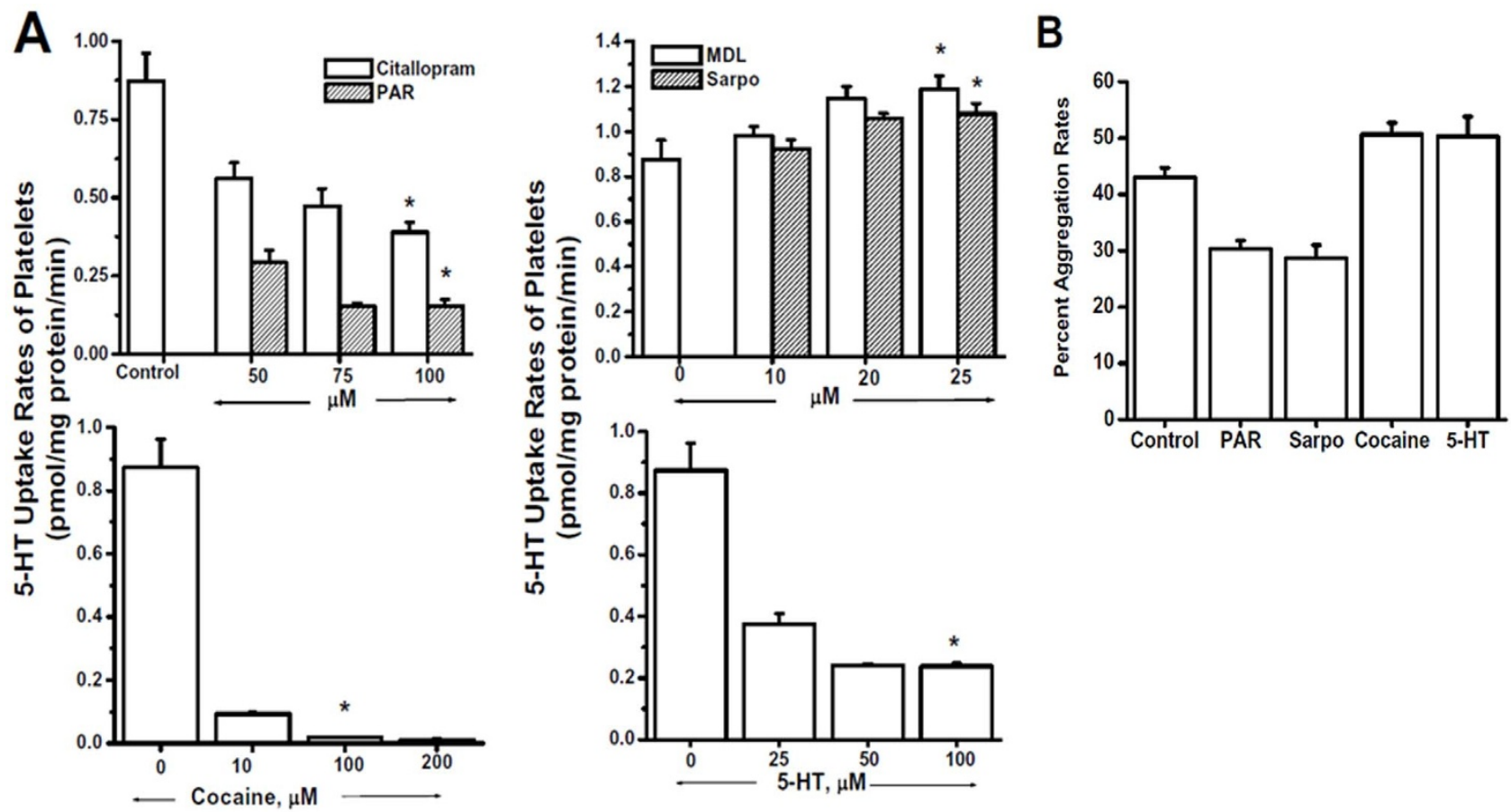

Figure 5 Isolated platelets of WT mice were pretreated with SSRI or 5- $\mathrm{HT}_{2 \mathrm{~A}}$ antagonists or cocaine or 5-HT. (A) $300 \mathrm{~K}$ platelets were incubated with various concentrations of citalopram, PAR, MDL, Sarpo, cocaine or 5-HT for $30 \mathrm{~min}$ at RT. Then, the 5-HT uptake rates were measured as described in the Method section. The in vitro treatments of all these reagents showed similar effect on the 5-HT rates as they did in in vivo treatments. (B) Percent aggregation in response to collagen $(3 \mu \mathrm{g} / \mathrm{ml})$ of isolated platelets pre-incubated in drug-free solution (control) or the listed drugs for 30 min. The aggregation response to collagen was significantly less in platelets incubated in PAR or Sarpo cocaine did not show a significant increase in their aggregation rates as it did in intraperitonal injection. These assays were performed in triplicate $(\mathrm{n}=5$ group). Asterisks indicate statistical difference between control- and drug treated $(*)$ platelets.

The SERT-dependent pathway is related with free levels of 5-HT present in platelet cytoplasm which binds to small GTPases, such as Rab4 and regulates the membrane trafficking of granules as well as SERT $^{22,21}$. Thus, selective 5-HT reuptake inhibitors (SSRI) downregulate the platelet 5-HT uptake rates which elevates the plasma 5-HT concentration yet blunts the aggregation rates of platelets via block- ing the 5-HT signaling in platelets ${ }^{13,14,21}$. These studies emphasize the importance of plasma $v$ s. platelet 5-HT ratio in platelet physiology.

One of our major findings was that platelets from cocaine-injected mice showed blunted 5-HT uptake rates by SERT resulting in a loss of the primary mechanism for regulating plasma levels of 5-HT and depletion of 5-HT signaling in the platelet cytosol. However, oppos-
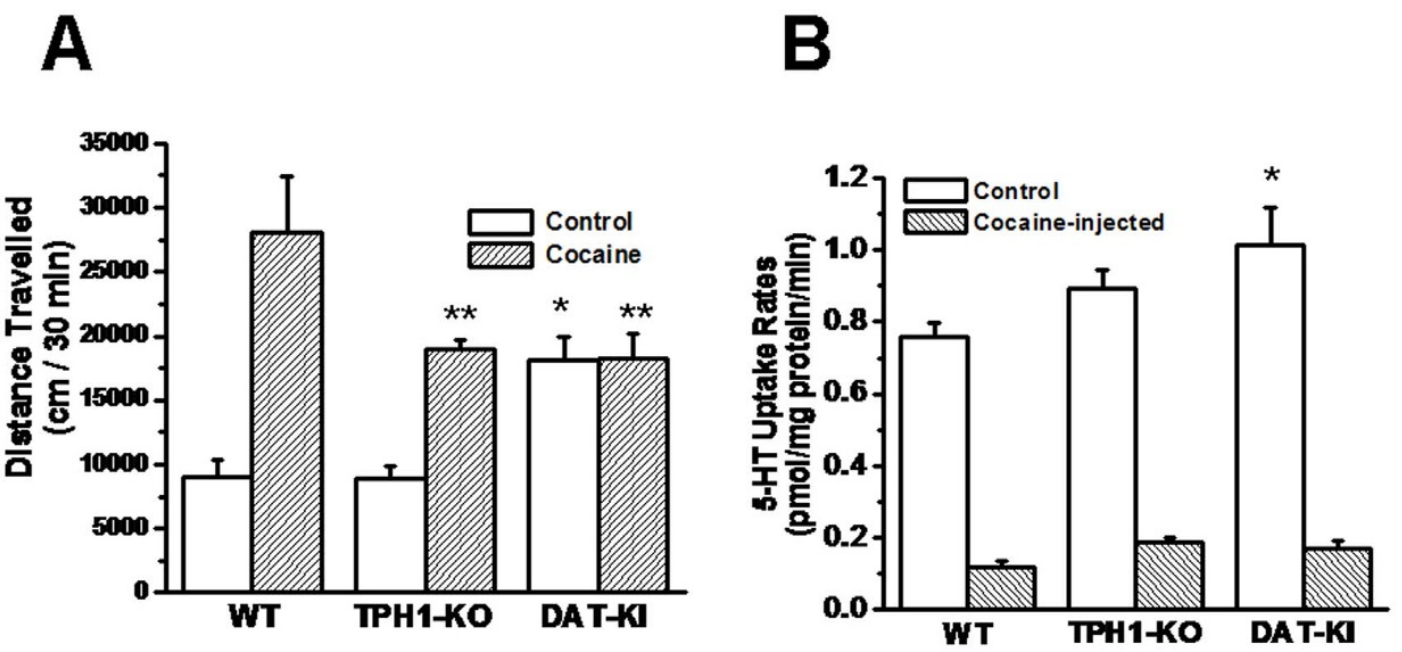

Figure $6 \mid$ (A) Locomotor Activity. WT, TPH1-KO and DAT-KI mice were injected either with $30 \mathrm{mg} / \mathrm{kg}$ cocaine or with saline. The basal locomotor activity of DAT-KI appeared 2-fold higher than the others however after cocaine-injection that was not changed. Cocaine-injection elevated the locomotor activity of WT mice by 3-fold and TPH1-KO by 2-fold. (B) 5-HT uptake rates of platelets. 5-HT uptake rates of the platelets isolated from DAT-KI was 33\% higher than the uptake rates of platelets isolated from WT mice. However, 5-HT uptake rates of platelets from all models showed $\sim 80 \%$ decrease following cocaine-injection. These assays were performed in triplicate ( $\mathrm{n}=5$ group). Asterisks indicate statistical difference between WT and DAT-KI $(*)$; cocaine-injected WT and cocaine-injected transgenic $\left({ }^{* *}\right)$ mice. 

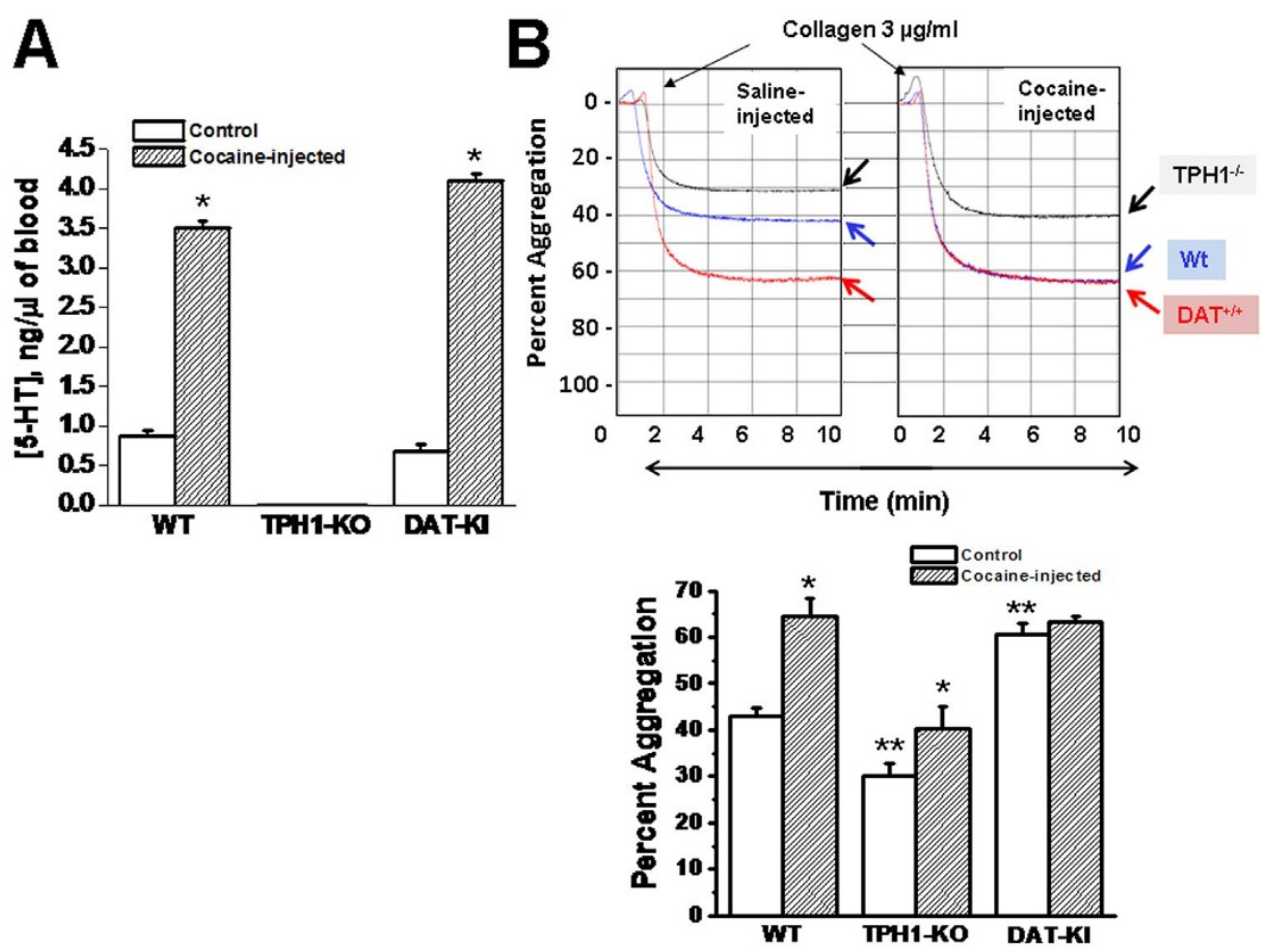

Figure $7 \mid$ (A) Blood 5-HT concentration. The 5-HT concentrations in blood plasma samples of the saline- and cocaine-injected WT, TPH1-KO and DAT-KI mice were measured by a competitive ELISA technique ${ }^{10}$. The plasma 5-HT level was too low to be detected in TPH1-KO mice. But in WT and DAT-KI plasma 5-HT levels were elevated by 4 - and 6-fold following cocaine-injection. All assays were performed in triplicate. $*=$ statistical difference between saline- and cocaine-injected mice ( $\mathrm{n}=5$ for each group). (B) The effect of cocaine on platelet aggregation was monitored. Platelets were isolated from saline- or cocaine-injected WT, TPH1-KO or DAT-KI mice and stimulated with collagen and their aggregation profile was monitored in an aggregometer. Approximately $30 \%$ of the platelets from saline-injected TPH1-KO mice and $43 \%$ of platelets from WT mice and $63 \%$ of the platelets from DAT-KI mice were aggregated at the end of $10 \mathrm{~min}$, whereas in the presence of cocaine, WT mice platelets showed $\sim 65 \%$ and the TPH1-KO mice platelets showed $\sim 40 \%$ and interestingly the DAT-KI mice platelets showed no elevation in aggregation. The average of 5 measurements is presented in the bar graph. Asterisks indicate statistical difference between control and cocaine-injected $\left(^{*}\right)$; WT and transgenic $(* *)$ mice $(\mathrm{n}=5$ group).

ite to the SSRI, cocaine elevates the aggregation rates of platelets. Experiments using the platelets of cocaine-insensitive DAT knockin transgenic mice, (DAT-CI) tested the involvement of sympathetic nervous system on platelet aggregation due to the fact that the effects of cocaine on CV system could be acting directly or via sympathetic nervous system. DAT-KI mice appeared to have higher 5-HT uptake rates, elevated plasma 5-HT level and higher platelet aggregation rate than the WT mice. Cocaine administration on DAT-KI mice reduced their 5-HT uptake rates significantly which caused an elevation in plasma 5-HT levels as found in cocaine-injected WT and peripheral 5 -HT KO (TPH1-KO). However cocaine did not change the aggregation rates of the platelets of DAT-KI mice suggesting the participation of the sympathetic nervous system in cocaine-mediated platelet aggregation process.

In an earlier study we showed that the elevated plasma 5-HT level increases the responses of platelets to collagen stimulation. The platelets of PAR-injected 5-HT infused mice showed attenuated aggregation. Similarly, platelets from Sarpo-injected 5-HT-infused mice have lower level of response to collagen stimulation. Here, using different selective 5 - $\mathrm{HT}_{2 \mathrm{~A}}$ or SERT blockers on wild-type mice before or after the infusion of 5-HT, an experimental model was created to mimic the cocaine-injected mice experiments. We observed a major effect of these drugs on platelet physiology.

When these drugs are administered on mice 24-hrs after the 5HT-infusion, they neither showed an effect on the 5-HT uptake rates of platelets nor their response to collagen stimulation. Because the impact of elevated 5-HT in plasma had already finalized its effects on platelets. The individual blocker reduced the 5-HT uptake rates of platelets to the level that was found in the plasma of cocaine-injected mice; contrary to cocaine, platelet hyper-reactivity was attenuated in the mice receiving blockers-injected prior to cocaine. Based on these findings, we hypothesize that cocaine mimics the combined effect that SERT and $5-\mathrm{HT}_{2 \mathrm{~A}}$ play together in a two-step process to propagate the platelet aggregation by additive effect of nonserotonergic catecholamine.

\section{Methods}

Animals. Adult male C57BL/6J wild-type (WT) mice, or TPH1-KO ${ }^{21}$ or DAT-KI ${ }^{24}$ mice on a C57BL6 genetic background were anesthetized with isoflurane for subcutaneous implantation of osmotic mini-pumps. Pumps were filled with saline (SAL) or $0.05 \mathrm{mg} / \mathrm{ml} 5-\mathrm{HT}$ dissolved in saline to provide an infusion rate of $1.66 \mu \mathrm{g} /$ $\mathrm{kg} / \mathrm{hr}^{13}$. Procedures involving animals were approved by the Institutional Animal Care and Use Committee at the University of Arkansas for Medical Sciences and were conducted in accordance with the NIH Guide for the Care and Use of Laboratory Animals.

Blood sampling and platelet preparation. After 24 hours of continuous infusion with either saline or 5-HT, blood was withdrawn into a syringe containing $3.8 \%$ sodium citrate solution by cardiac puncture from each animal. Samples of platelet and plasma were prepared from the whole blood ${ }^{13}$. In biochemical studies, each assay was performed using the same number $300,000 / \mu \mathrm{L}$ of platelets. The concentrations of $5-$ HT in platelets and plasma were quantified by competitive enzyme-linked immunosorbent assay (ELISA). The platelet 5-HT uptake assay was performed as described ${ }^{10}$

Quantitative measurement of 5HT levels by ELISA. The 5-HT levels in plasma which were prepared from the blood samples of each animal model was measured by competitive ELISA technique by following the manufacturer's instructions (IBL Immuno-Biological Laboratories, Hamburg, Germany) as described previously ${ }^{10,13}$

Platelet 5HT uptake assay. Platelet $(300,000 / \mu \mathrm{L}$ of platelets) pellet was quickly washed with phosphate-buffered saline (PBS) containing $0.1 \mathrm{mM} \mathrm{CaCl}_{2}$ and $1 \mathrm{mM}$ $\mathrm{MgCl}_{2}$ (PBSCM) then resuspended in PBSCM with $14.6 \mathrm{nM} \mathrm{3H-5-HT}$ at room 
temperature (RT) for $10 \mathrm{~min}$, to include only the initial linear phase of transport in human platelets ${ }^{10,13}$. Platelets were collected by rapid filtration through Whatman GF/ $B$ filters and were washed twice with $5 \mathrm{ml}$ of ice-cold PBS. Filters were placed in scintillation vials containing $5 \mathrm{ml}$ scintillation cocktail and immediately counted.

Background accumulation of 3H-5-HT that occurred independent of SERT was measured in the same experiment treating platelets with the high-affinity cocaine analog, $0.1 \mu \mathrm{M} 2 \beta$-carbomethoxy-3-tropane ( $\beta$-CIT) (Chemical Synthesis Service, NIMH, Bethesda, MD) and subtracted from each experimental value ${ }^{10,13}$. In parallel, the protein concentration for $0.2 \mathrm{X} 106$ ( $0.015 \mathrm{mg}$ cellular protein) platelets was determined using the Micro BCA protein Assay Kit. The 5-HT uptake rates of transporters were calculated as means of standard deviation values from three independent experiments.

Stirred platelet aggregation. For aggregation assays, platelets in plasma was prepared and platelet counts were normalized $(300,000 / \mu \mathrm{L})$ using a Hemavet 950 (Drew Scientific, Waterbury, CT). Collagen $(3 \mu \mathrm{g} / \mathrm{ml})$ was monitored by light transmittance (Chrono-log Corp., Havertown, PA) ${ }^{13,17}$.

Flow cytometry. All flow cytometry experiments were performed in the UAMS Flow Cytometry Core Facility. The impact of stimulants such as 5-HT, cocaine or other drugs on platelet activation was assessed using anti-P-selectin (Emfret Analytics, Cat $\mathrm{M} 130-1)$. Platelets in plasma $(300,000 / \mu \mathrm{L})$ were incubated with the $\mathrm{Ab}$ and followed the procedure reported previously ${ }^{13,17}$. The samples were gated for single platelets based on forward and side scatter profiles and 20,000 events were recorded and read at the UAMS Flow Cytometry Core Facility.

Data analysis. Nonlinear regression fits of experimental and calculated data were performed with Origin, which uses the Marquardt-Levenberg non-linear least squares curve fitting algorithm. Each figure shows a representative experiment that was performed at least three times. The statistical analysis given in the Results section is from multiple experiments. Data with error bars represent as mean \pm SD for triplicate samples. Data were analyzed by ANOVA (analysis of variance) to compare data sets and two-sided t-tests based on the ANOVA mean squared error.

1. Heesch, C. M. et al. Cocaine activates platelets and increases the formation of circulating platelet containing microaggregates in humans. Heart. 83, 688-695 (2000).

2. Kugelmass, A. D., Oda, A., Monahan, K., Cabral, C. \& Ware, J. A. Activation of human platelets by cocaine. Circulation. 88, 876-883 (1993).

3. Kugelmass, A. D. \& Ware, J. A. Cocaine and coronary artery thrombosis. Ann Intern Med. 116, 776-777 (1992).

4. Giros, B. et al. Cloning, pharmacological characterization, and chromosome assignment of the human dopamine transporter. Mol Pharmacol. 42, 383-390 (1992).

5. Pacholczyk, T., Blakely, R. D. \& Amara, S. G. Expression cloning of a cocaine- and antidepressant-sensitive human noradrenaline transporter. Nature. 350, 350-354 (1991)

6. Ramamoorthy, S. et al. Antidepressant- and cocaine-sensitive human serotonin transporter: molecular cloning, expression, and chromosomal localization. Proc.Natl.Acad.Sci. USA. 90, 2542-2546 (1993).

7. Rinder, H. M., Ault, K. A., Jatlow, P. I., Kosten, T. R. \& Smith, B. R. Platelet $\alpha-$ granule release in cocaine users. Circulation. 90, 1162-1167 (1994).

8. Oruch, R., Lund, A., Pryme, I. F. \& Holmsen, H. An intercalation mechanism as a mode of action exerted by psychotropic drugs: results of altered phospholipid substrate availabilities in membranes? J Chem Biol. 3, 67-88 (2010).

9. Brunk, I. et al. The first luminal domain of vesicular monoamine transporters mediates G-protein-dependent regulation of transmitter uptake. J Biol Chem. 281, 33373-33385 (2006).

10. Brenner, B. et al. Plasma serotonin level and the platelet serotonin transporter. J. Neurochem. 102, 206-216 (2007).

11. Holmsen, H. \& Weiss, H. J. Secretable storage pools in platelets. Annu Rev Med 30, 119-134 (1979).

12. Rudnick, G. \& Clark, J. From synapse to vesicle: The re-uptake and storage of biogenic amine neurotransmitters. Biochemica et Biophysica. Acta 1144, 249-263 (1993).

13. Ziu, E. et al. Down-regulation of the Serotonin Transporter in hyperreactive platelets counteracts the pro-thrombotic effect of serotonin. J Mol Cell Cardiol. 5, 1112-1121 (2012)

14. Ottervanger, J. P., Stricker, B. H., Huls, J. \& Weeda, J. N. Bleeding attributed to the intake of paroxetine. Am J Psychiatry 151, 781-782 (1994).

15. Carneiro, A. M., Cook, E. H., Murphy, D. L. \& Blakely, R. D. Interactions between integrin alphaIIbbeta3 and the serotonin transporter regulate serotonin transport and platelet aggregation in mice and humans. J Clin Invest 118, 1544-1552 (2008).

16. Sato, N. et al. Characterization of monoclonal antibodies against mouse and rat platelet glycoprotein V (CD42d). Hybridoma 19, 455-461 (2000).

17. Mercado, C. P. et al. A serotonin-induced N-glycan switch regulates platelet aggregation. Sci. Rep 3, 2795; doi:10.1038/srep02795 (2013)

18. Berry, C. N. et al. Antiplatelet and antithrombotic activity of SL65.0472, a mixed 5HT1B/5-HT2A receptor antagonist. Thromb Haemost 85, 521-528 (2001).
19. Przyklenk, K. Targeted inhibition of the serotonin 5-HT2A receptor improves coronary patency in an in vivo model of recurrent thrombosis. J Thromb Haemost. 8, 331-340 (2010).

20. Nishihira, K. Inhibition of 5-hydroxytryptamine receptor prevents occlusive thrombus formation on neointima of the rabbit femoral artery. J Thromb Haemost. 4, 247-255 (2006)

21. Walther, D. J. et al. Serotonylation of small GTPases is a signal transduction pathway that triggers platelet alpha-granule release. Cell 115, 851-862 (2003).

22. Shirakawa, R. et al. Small GTPase Rab4 regulates Ca2+-induced $\alpha$-granule secretion in platelets. J. Biol. Chem. 275, 33844-33849 (2000).

23. Ahmed, B. A. et al. Serotonin transamidates Rab4 and facilitates its binding to the C terminus of serotonin transporter. J Biol Chem 283, 9388-9398 (2008).

24. Chen, R. et al. Abolished cocaine reward in mice with a cocaine-insensitive dopamine transporter. Proc Natl Acad Sci U S A. 103, 9333-9338 (2006).

25. Abdelmalik, N. et al. Effect of the selective serotonin reuptake inhibitor paroxetine on platelet function is modified by a SLC6A4 serotonin transporter polymorphism. J Thromb Haemost. 6, 2168-74 (2008).

26. Schmidt, C. J., Fadayel, G. M., Sullivan, C. K. \& Taylor, V. L. 5-HT2 receptors exert a state-dependent regulation of dopaminergic function: studies with MDL 100,907 and the amphetamine analogue, 3,4-methylenedioxymethamphet amine. Eur J Pharmacol. 223, 65-74 (1992).

27. NACO. The cocaine epidemic in America, in: The National Association of Counties. 2005.http://www.naco.org/newsroom/countynews/archives/Pages/ default.aspx Date of access: 02/07/2011.

28. DASIS. Substance abuse treatment admissions (TEDS) for 2006. http://www.oas. samhsa.gov/DASIS.htm Date of access: 02/07/2011

29. Stenberg, R. G., Winniford, M. D., Hillis, L. D., Dowling, G. P. \& Buja, L. M. Simultaneous acute thrombosis of two major coronary arteries following intravenous cocaine use. Arch Pathol Lab Med. 113, 521-524 (1989).

30. Moliterno, D. J. et al. Influence of intranasal cocaine on plasma constituents associated with endogenous thrombosis and thrombolysis. Am J Med. 96, 492-496 (1994)

31. Rinder, H. M., Ault, K. A., Jatlow, P. I., Kosten, T. R. \& Smith, B. R. Platelet $\alpha-$ granule release in cocaine users. Circulation. 90, 1162-1167 (1994).

32. Rezkalla, S. H., Mazza, J. J., Kloner, R. A., Tillema, V. \& Chang, S. H. Effects of cocaine on human platelets in healthy subjects. Am J Cardiol. 72, 243-246 (1993).

33. McCord, J. et al. Management of cocaine-associated chest pain and myocardial infarction: a scientific statement from the American Heart Association Acute Cardiac Care Committee of the Council on Clinical Cardiology. Circulation. 117, 1897-1907 (2008).

34. Kolodgie, F. D., Virmani, R., Cornhill, J. F., Herderick, E. E. \& Smialek, J. Increase in atherosclerosis and adventitial mast cells in cocaine abusers: an alternative mechanism of cocaine-associated coronary vasospasm and thrombosis. J Am Coll Cardiol. 17, 1553-1560 (1991).

35. Vanhoutte, P. M. Platelet-derived serotonin, the endothelium, and cardiovascular disease. J. Cardiovasc. Pharmacol. 17, (Suppl. 5) S6-12 (1991).

36. Reed, G. L. Platelet Secretion Platelets. Michelson, A.D. (ed), 309-319 (Academic Press, 2006).

37. White, J. G. Platelet Structure Platelets. Michelson, A.D. (ed), 45-75 (Academic Press, 2006).

38. De Clerck, F. F. \& Herman, A. G. 5-Hydroxytryptamine and platelet aggregation. Fed Proc. 42, 228-232 (1983).

39. De Clerck, F. F. \& Janssen, P. A. Amplification mechanisms in platelet activation and arterial thrombosis. J Hypertens. 8, S87-93 (1990)

\section{Acknowledgments}

We gratefully acknowledge NIDA for supplying us cocaine for these studies. We thank Mr. Terry Fletcher for assistance in animal handling and the UAMS Department of Animal Laboratory Medicine (DLAM) and Flow Cytometry Core. This work was supported by the IDeA program-P30 GM110702 from National Institutes of Health-NIGMS; American Heart Association [GRNT17240014] and by the National Institutes of Health, NHLBI [R01HL091196 and R01HL091196-01A2W1] to FK.

\section{Author contributions}

F.K. designed and directed the project; E.Z., C.H., Y.L., C.L.L., P.S., S.S.U., C.M. conducted experiments. E.Z., Y.L., H.H.G., F.K. analyzed the data. H.H.G., F.K. participated in manuscript writing and scientific discussions, giving detailed feedback in all areas of the project.

\section{Additional information}

Competing financial interests: The authors declare no competing financial interests.

How to cite this article: Ziu, E. et al. Effect of serotonin on platelet function in cocaine exposed blood. Sci. Rep. 4, 5945; DOI:10.1038/srep05945 (2014). 

NoDerivs 4.0 International License. The images or other third party material in this article are included in the article's Creative Commons license, unless indicated otherwise in the credit line; if the material is not included under the Creative
Commons license, users will need to obtain permission from the license holder in order to reproduce the material. To view a copy of this license, visit http:// creativecommons.org/licenses/by-nc-nd/4.0/ 